\title{
Expansão escolar pública e privada na periferia de São Paulo (1900-1964)
}

\author{
Adriana Santiago Rosa Dantas ${ }^{1}$ \\ Orcid: 0000-0003-1066-7063
}

\section{Resumo}

Este artigo tem como tema a expansão das escolas públicas e privadas da periferia leste de São Paulo nas primeiras décadas do século XX. A pesquisa originária que resultou neste texto teve como objeto a expansão da escola privada na Zona Leste de São Paulo, cuja hipótese inicial era de que tal expansão não era um fenômeno recente do novo milênio, mas que aconteceria desde o século XX. Hipótese comprovada, os dados demonstram que a expansão privada foi concomitante com a formação da periferia leste. Para tanto foram produzidos mapas desta expansão no tempo e no espaço, a partir de dados quantitativos das escolas públicas e privadas da Zona Leste de São Paulo fornecidos pela Secretaria Estadual de Educação (SEE). A técnica utilizada para a elaboração dos mapas foi o georreferenciamento. A análise foi realizada a partir da releitura da literatura sobre educação e periferia, considerando as relações raciais para discutir o crescimento das escolas públicas e privadas. A investigação permitiu concluir que a expansão da escola privada esteve presente durante a formação da periferia leste, além de confırmar a participação popular na contribuição da expansão da escola pública na região.

\section{Palavras-chave}

Escolas privadas - Escolas públicas - Periferia - Expansão escolar - Relações raciais.

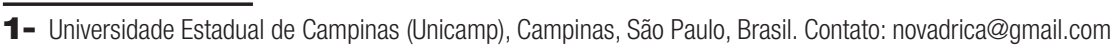




\title{
The expansion of public and private schools in the outskirts of São Paulo (1900-1964)*
}

\section{Abstract}

This article deals with the expansion of public and private schools in the East periphery of the city of São Paulo in the first decades of the 20th century. The original research, which resulted in this text, studied the expansion of private school in the East region of the city. Our initial hypothesis was that this expansion was not a phenomenon from the new millennium, but that would have been happening since the 20th century. The hypothesis was proved; as data has shown that the private expansion was concomitant with the formation of the East periphery. We used georeferencing to create maps of this expansion in time and space from quantitative data of public and private schools in the East region of São Paulo provided by the State Secretary of Education. Our analysis was based on the literature about education and peripheries, considering racial relations to discuss the growth of public and private schools. We concluded that the expansion of private schools was always present during the formation of the East periphery. We also confirm the popular participation in contributing for the expansion of public school in the region.

\section{Keywords}

Private schools - Public schools - Periphery - School expansion - Racial relations

\section{Introdução}

\begin{abstract}
Nosso tema é o óbvio. Acho mesmo que os cientistas trabalham é com o óbvio. O negócio deles - nosso negócio - é lidar com o óbvio.

Darcy Ribeiro (“Sobre o óbvio”).
\end{abstract}

0 sistema de ensino brasileiro é constituído das escolas públicas e privadas segundo a Lei 9.393/1996 de Diretrizes e Bases da Educação Nacional (BRASIL, 1996). Apesar da obviedade desta afırmação, tomar este sistema como objeto de estudo em sua totalidade, isto é, comparando as duas dependências administrativas, não tem sido usual na área da sociologia da educação ${ }^{3}$. Uma primeira implicação a esta constatação consiste em não analisar tal sistema considerando sua mais profunda contradição social que separa as

\footnotetext{
2- Agradeço a leitura prévia de Gabriela Valente e aos pareceristas que apontaram pontos cruciais de ajustes. Evidentemente, as incorreções que persistem são de minha responsabilidade. A pesquisa de doutorado que resultou neste artigo teve a orientação da profa. Dra. Maria da Graça Jacintho Setton. A investigação foi financiada pela Capes/Fapesp (Processo 2015/05846-0), às quais estendo os meus agradecimentos.

3- Um dos trabalhos que buscam fazer a comparação no espaço social entre as escolas pública e privada em São Paulo é o de Perosa, Lebaron e Leite (2015), que demonstram a correlação entre a formação privada nos lugares mais ricos, com o grupo de maior formação educação e melhor posição profissional.
} 
escolas pelos públicos segundo sua condição econômica, o que caracteriza as desigualdades educacionais no Brasil.

Outra implicação em não estudar o sistema de ensino em sua totalidade obscurece a naturalização de que o modelo de escola de qualidade no Brasil é o privado ${ }^{4}$, sem a crítica do que isso representa no conflito social ${ }^{5}$. Apregoa-se que a educação brasileira não é de qualidade, ofuscando o fato de que existe uma educação que "funciona" e atende a um grupo muito específico, que tem condições de pagar por essa educação. Consequentemente, os melhores postos de trabalho são ocupados por aqueles que tiveram seu percurso escolar em escolas privadas no ensino básico (ALMEIDA; NOGUEIRA, 2003; ALMEIDA, 2009; MENEZES FILHO; KIRSCHBAUM, 2015; SETTON; MARTUCCELLI, 2015). Ressalta-se, todavia, o argumento neoliberal da qualidade do privado em detrimento do público como justificativa da diminuição do Estado, tão bem analisado por críticos, tais como Fonseca (1992), Gentili (1995) e Oliveira (2009). No entanto, esse não será o viés discutido, interessando a este texto a naturalização da construção social do argumento da qualidade da escola privada.

A complexidade se intensifica ao se associar a intersecção das relações raciais à problemática das desigualdades educacionais pela via econômica, pois a pobreza tem cor no Brasil, a negra. Estudos clássicos no final do século XX, como os de Hasenbalg e Silva (1999), demonstraram que o componente racial tem sido desconsiderado ou minimizado nas análises sobre estratificação social, não expondo a funcionalidade da discriminação racial no processo de competição na estrutura social, na qual os negros estão em desvantagem. Processo dado pelo racismo estrutural (ALMEIDA, 2018) que resulta na desigualdade de oportunidades entre brancos e não brancos pois, para estes últimos, em suas trajetórias, tem um "déficit de mobilidade social ascendente" e um "processo de acumulação de desvantagens" (HASENBALG; SILVA, 1999, p. 218). Estas estão associadas à discrepância educacional que separava os brancos dos pretos e pardos, sendo estes portadores de um déficit educacional, conforme corroborou Lima (1999), nesta mesma coletânea. Estudos mais recentes do século XXI indicam que os brancos estão superrepresentados nas escolas privadas e que os negros estão nas escolas públicas (MENEZES FILHO; KIRSCHBAUM, 2015, p. 123-124), sendo o fator racial um dos mais persistentes nas desigualdades educacionais e profissionais (LIMA; PRATES, 2015). Grosso modo, a escola de quem pode pagar tem sua maioria branca enquanto a escola pública, de menor qualidade, está destinada à maioria negra.

Estudos recentes têm demonstrado que as classes populares têm optado pela escola privada (CAMELO, 2014; SIQUEIRA; NOGUEIRA, 2017). Primeiramente, associou-se esse fenômeno ao aumento de renda proporcionado pelo governo petista a partir dos anos 2000 (NOGUEIRA, 2013). Entretanto, outros estudos demonstraram que a expansão privada já acontecia desde os anos de 1980, na cidade de São Paulo (DANTAS, 2013, 2018; MEDEIROS; JANUÁRIO, 2014). Por sua vez, este artigo vem demonstrar que o crescimento

4- As escolas públicas de qualidade se assemelham ao que foi estudado por Gomes e Nogueira (2017), pois são seletivas no processo de ingresso, a carga horária e remuneração dos professores são diferenciadas, dentre outros fatores que distinguem algumas instituições pela excelência, mas que não estão disponíveis para todos.

5- A tradição sociológica do conflito pode ser vista em Collins (2009). 
da escola privada foi anterior, concomitante com a formação da periferia leste de São Paulo (DANTAS, 2018).

Este texto apresenta os resultados de uma pesquisa de doutorado, a qual teve como preocupação convergir o histórico urbano da formação da periferia leste de São Paulo com a expansão das escolas públicas e privadas da região. A hipótese inicial era de que isso não se tratava de um fenômeno recente do novo milênio, mas que aconteceria desde o século XX. A problemática que se levantou dizia respeito ao questionamento de qual seria o sentido de já haver escola privada desde o início do século XX, em uma região considerada periférica. Se a escola privada da periferia não era um fenômeno recente, por que ela esteve "oculta" nos estudos e análises sobre a região? Que tipo de relação haveria com a expansão da escola pública na periferia, fenômeno estudado por Sposito (2002)? Parte das conclusões teóricas será apresentada neste texto.

Metodologicamente foram utilizados dados quantitativos das escolas públicas e privadas da Zona Leste de São Paulo fornecidos pela Secretaria Estadual de Educação (SEE), que foram cruzados com os dados de georreferenciamento das escolas paulistanas do Centro de Estudo da Metrópole $(\mathrm{CEM})^{6}$, produzindo mapas da expansão no tempo e no espaço. Os dados da SEE consistiam de escolas privadas ainda ativas (aquelas que foram fechadas ao longo do tempo não estavam mais disponíveis, por isso não constam nos mapas), indicando que o número destas instituições devesse ser maior. Os resultados demonstraram que, desde 1918, estabelecimentos privados, sobretudo confessionais, estavam sendo fundados na Zona Leste de São Paulo.

Além desta introdução, o artigo se divide em quatro partes. A primeira discute o escopo da pesquisa, a Zona Leste de São Paulo e sua formação. Em seguida, há a apresentação dos dados das escolas no período de 1900 a 1945, correspondente à imigração europeia. A terceira parte dedica-se aos dados do momento da migração interna que sofreu a região, colocando como limite da periodização os anos de 1960, época da ditadura militar, cujos processos educacionais trouxeram algumas outras dinâmicas que não caberiam neste artigo. 0 texto termina com as considerações finais.

\section{A formação da Zona Leste de São Paulo (1900-1960)}

0 município de São Paulo tem 11.704.613 habitantes segundo as estimativas ofıciais da prefeitura de São Paulo para 2019. Ele está dividido em cinco zonas: Centro (473.798 habitantes), Leste (4.015.583), Oeste (1.093.020), Norte (2.274.465) e Sul $(3.847 .747)^{7}$.

\footnotetext{
6- Trata-se de uma instituição de pesquisa sediada na Faculdade de Filosofia, Letras e Ciências Humanas da Universidade de São Paulo, composta por um grupo multidisciplinar de pesquisadores das ciências sociais. Agradeço ao curso do CEM oferecido pelo geógrafo Daniel Waldvogel, cuja ajuda permitiu montar e preparar o banco de dados para fazer os mapas.

7- Fonte: Infocidade. Disponível em https://www.prefeitura.sp.gov.br/cidade/secretarias/upload/urbanismo/infocidade/htmls/7_populacao_ censitaria_e_projecoes_populac_2008_10573.html. Acessado em 29 jul. 2019.
} 
Mapa 1- Município de São Paulo por prefeituras regionais (antigas subprefeituras)

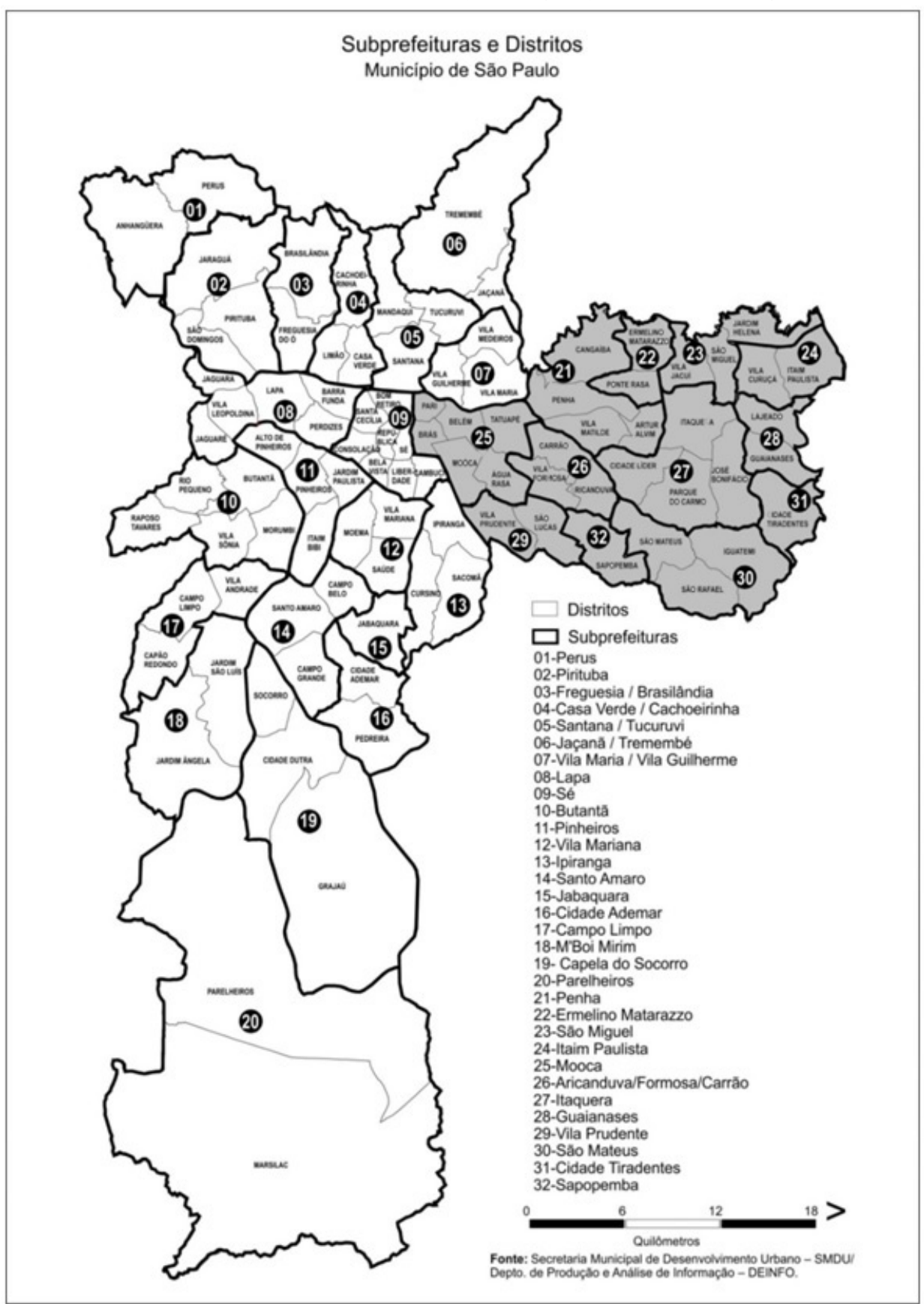

Fonte: Infocidade - Regiões, Subprefeituras e Distritos. Disponível em: http://infocidade.prefeitura.sp.gov.br/mapas/3_regioes_subprefeituras_e_ distritos_2014_10338.pdf > Acesso em: 27 de ago. 2016. Tratado por Alessandra Dantas. 
A cidade está, também, organizada em 32 prefeituras regionais (antigas subprefeituras), totalizando 98 distritos distribuídos entre elas. 0 escopo escolhido para análise foi a Zona Leste de São Paulo, doravante ZL, destacada em cinza no Mapa 1. A ZL é a região mais populosa do município de São Paulo, correspondendo a 35,5\% dos munícipes, e engloba 12 prefeituras regionais e 33 distritos (conforme a Tabela 1).

Tabela 1- Prefeituras Regionais e Distritos da ZL

\begin{tabular}{ccc}
\hline Prefeitura Regional & $\vdots$ & Distritos \\
\hline Aricanduva & $\vdots$ & Aricanduva, Carrão e Vila Formosa \\
\hline Cidade Tiradentes & $\vdots$ & Cidade Tiradentes \\
\hline Ermelino Matarazzo & $\vdots$ & Guaianases, Lajeado \\
\hline Guaianases & $\vdots$ & Itaim Paulista, Vila Curuçá \\
\hline Itaim Paulista & $\vdots$ & Cidade Líder, Itaquera, José Bonifácio e Parque do Carmo \\
\hline Itaquera & Água Rasa, Belém, Brás, Mooca, Pari e Tatuapé \\
\hline Mooca & $\vdots$ & Artur Alvim, Cangaíba, Penha, Vila Matilde \\
\hline Penha & Iguatemi, São Mateus e São Rafael \\
\hline São Mateus & $\vdots$ & Jardim Helena, São Miguel e Vila Jacuí \\
\hline São Miguel & $\vdots$ & Sapopemba \\
\hline Sapopemba & $\vdots$ & São Lucas e Vila Prudente \\
\hline Vila Prudente &
\end{tabular}

Fonte: Infocidade (2018). Elaboração própria.

A ZL passou por um processo de ocupação que intercruza a questão a racial, porém não discutida tradicionalmente por esse viés nos estudos urbanos e historiográficos. Contudo, desde o começo do século XX, esta zona recebeu uma ocupação imigrante nas primeiras décadas e uma ocupação migrante depois dos anos de 1930 (DANTAS, 2013), cujo componente racial estava presente, como será discutido adiante. Por outro lado, os negros que habitavam em São Paulo desde o século XIX estavam sendo deslocados para territórios à margem dos grandes centros (ROLNIK, 1989). Tal dinâmica contribuiu para o crescimento demográfico, pois em 1900, São Paulo tinha 239.820 habitantes e em 1920 mais que dobrou sua população para 579.033 habitantes ${ }^{8}$.

A ocupação imigrante está relacionada à transição da abolição da escravatura e o trabalho livre. O Estado de São Paulo, no século XIX, foi beneficiado com a construção de linhas férreas que favoreceu o início de variadas atividades como as agrícolas, comerciais e industriais, retirando a região do isolamento (CARONE, 2001; DEAN, 1991; MORSE, 1970). No contexto de modernização industrial, estudos indicam que São Paulo substituiu o trabalho dos negros, outrora escravizados, pelos europeus, especialmente os italianos (ANDRADE, 1994). 0 principal componente racial daquele momento era o processo de branqueamento, balizado pelas teorias eugênicas, incentivando a imigração europeia na cidade (DOMINGUES, 2004; LARA, 1988; GÓES, 2015). Os negros que estavam sendo afastados para locais menos valorizados (ROLNIK, 1989) também foram sendo "apagados" da história como não participantes do crescimento da cidade que se modernizava, fato este contestado por estudos recentes (SANTOS, 2008).

8- Fonte: IBGE e Censos Demográficos. Disponível em: http://smul.prefeitura.sp.gov.br/historico_demografico/tabelas.php Acesso em: 25 ago. 2018. 
Em 1877, a linha do trem passou pelo bairro do Brás na ZL tornando seu entorno e a região de Belém e Mooca em um dos primeiros subúrbios populares, ocupados por italianos, espanhóis, portugueses que foram trabalhar nas fábricas que se instalavam vizinhas à linha férrea. Foi nessa região que se estabeleceram as primeiras indústrias de bens de consumo (ANDRADE, 1994; ROLNIK, 2003). Muitos imigrantes vieram a ser pequenos industriais e alguns se tornaram grandes, como é o caso da família italiana Matarazzo, maior representante das indústrias têxteis do século XX, responsável por aquela que deu nome a um dos distritos da ZL, Ermelino Matarazzo (DANTAS, 2013; MARTINS, 1974).

A urbanização da Mooca, Tatuapé e Penha se deu entre 1915 e 1929, conforme o mapa 2. A ocupação imigrante era socialmente desprestigiada em relação aos grandes bairros, era parte do subúrbio, mais precário, considerado uma "outra cidade" de sotaque italiano (ANDRADE, 1994). Depois do processo de gentrificação na segunda metade do século XX, transformou-se na região com os distritos mais valorizados da ZL, sobretudo a Mooca e o Tatuapé.

Mapa 2- Área urbanizada (1930-1949)

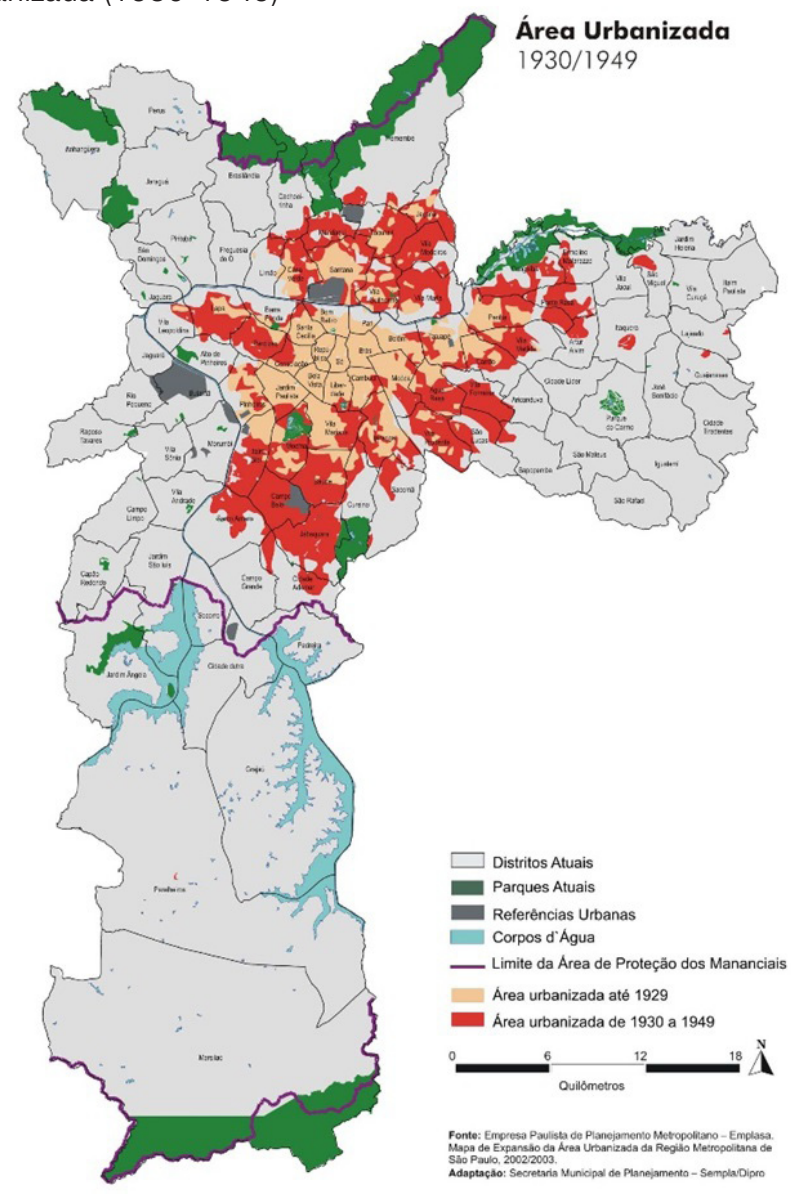

Fonte: Histórico Demográfico do Município de São Paulo. Disponível em: http://smul.prefeitura.sp.gov.br/historico_demografico/1960.php. Acesso em: 25 set. 2018. 
A ocupação migrante, por sua vez, derivou de políticas estatais do governo de Getúlio Vargas (1930-1945) que buscaram mudar o perfil do operariado pelo incentivo da mão-de-obra nacional em detrimento da estrangeira. Naquele governo, o liberalismo da Velha República não se enquadrava no período populista, na concepção de Ribeiro (2001), pois o tipo de nação a ser construída necessitava de maior intervenção estatal a fim de enfrentar a pobreza através de políticas que valorizassem o trabalho como estratégia de ascensão social. Naquele contexto, São Paulo recebeu migrantes internos vindos do Norte e Nordeste, fazendo a população triplicar em 20 anos, pois a cidade tinha 1.326.261 habitantes em 1940 e passou para 3.781.446 em 1960', ampliando a mancha urbana para o leste, conforme o Mapa 3.

Mapa 3- Área urbanizada (1950-1960)

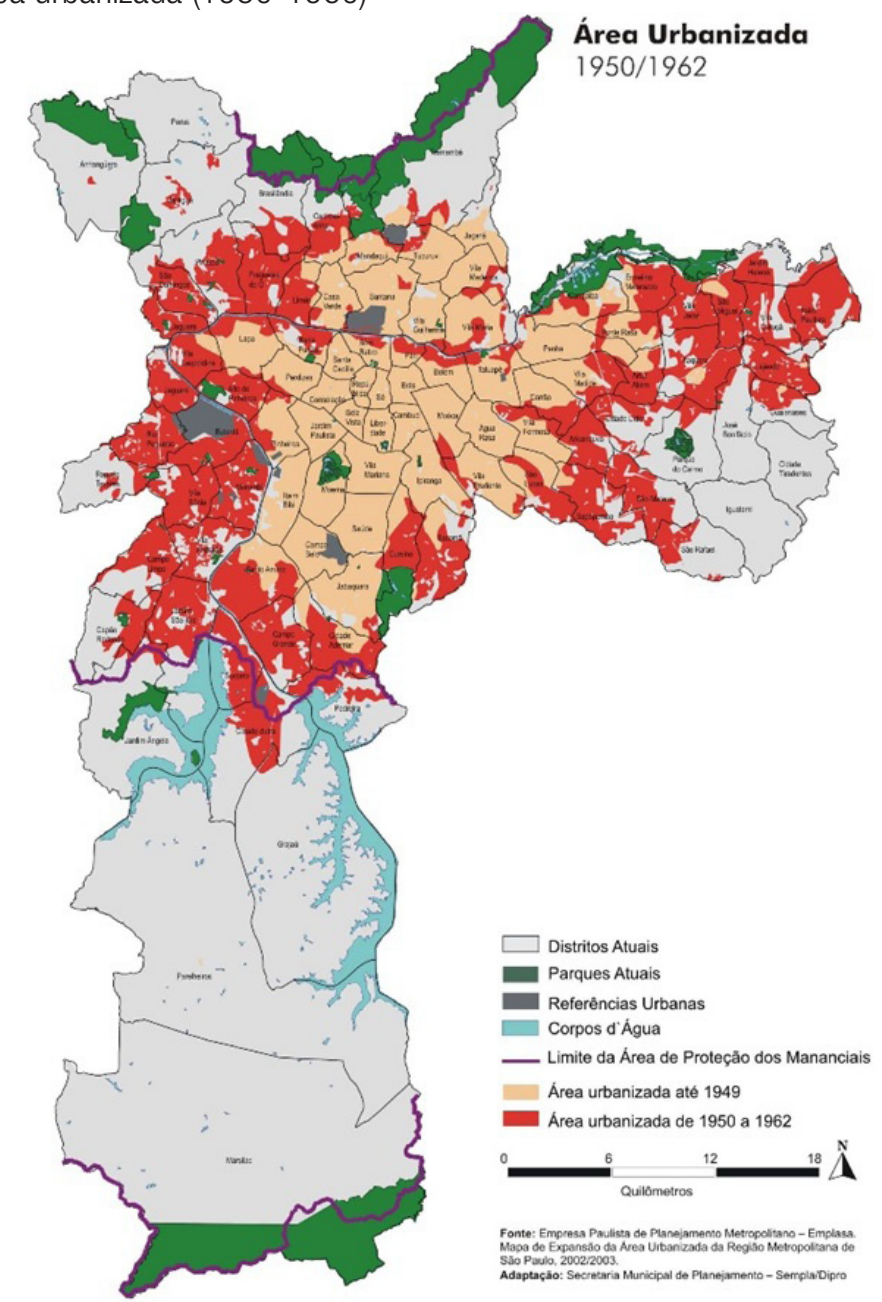

Fonte: Histórico Demográfico do Município de São Paulo. Disponível em: http://smul.prefeitura.sp.gov.br/historico_demografico/1960.php. Acesso em: 18 ago. 2020.

9- Fonte: IBGE, Censos Demográficos. Disponível em: http://smul.prefeitura.sp.gov.br/historico_demografico/tabelas.php. Acesso em: 25 ago. 2018. 
A chegada da indústria Nitro Química em São Miguel Paulista em 1935 pode ser considerado um marco da ocupação migrante na ZL. Ela foi instalada na várzea do Rio Tietê e no entorno da estrada de ferro, pois o trem facilitaria a instalação do maquinário que era importado dos Estados Unidos, fatores que contribuíam para a efetivação da instalação dessa indústria (FONTES, 1997, p. 29-30). 0 distrito de São Miguel Paulista e adjacências ficaram conhecidos como a "nova Bahia" pelo grande número de nordestinos que vieram trabalhar na indústria, modificando a paisagem urbana da região (FONTES, 2008, p. 92). Os nacionais eram estigmatizados, conhecidos pela pecha de "baianos" por serem o maior número de migrantes e, nessa classificação, “[...] é importante não desconsiderar o componente racial implícito na designação" (FONTES, 2008, p. 70), pois eles eram negros em sua maioria. A população de maioria branca da ocupação imigrante teve uma significativa mudança com a vinda de migrantes negros.

Além do processo de branqueamento ou europeização na cidade de São Paulo, ocorreu outro fenômeno de distinção social, que Albuquerque Jr. (2009) denomina de “invenção do Nordeste". Para o autor, foi "inventada" uma representação negativa do Nordeste pelo Sul, que se modernizava. No conflito social que se estabeleceu com a chegada dos migrantes internos em relação aos imigrantes que vieram para estabelecer uma mão-de-obra "mais qualificada”, “[...] longe de parceiros do desenvolvimento, os migrantes nordestinos eram considerados culpados e eventuais 'bodes expiatórios' pelas agruras advindas do rápido crescimento da cidade" (FONTES, 2008, p. 72). Fato corroborado por Magalhães (2011), que indica em seu estudo que os nordestinos que se transferiam para a ZL sentiam o preconceito por parte dos antigos moradores, descendentes de imigrantes, em uma separação simbólica entre os estabelecidos e os outsiders (ELIAS; SCOTSON, 2000).

Essa segunda ocupação é analisada pelos estudos clássicos da periferia que demonstraram que várias regiões, como a ZL, passaram por um processo de espoliação urbana, na qual a classe trabalhadora foi submetida a uma superexploração ao ser espoliada também de infraestrutura básica (CAMARGO et al., 1976; KOWARICK, 1993). Enquanto na fase da ocupação imigrante havia vilas operárias para essa classe trabalhadora, no período da ocupação migrante a classe trabalhadora era responsável por sua moradia por meio da autoconstrução e, mais tarde, formando favelas (MARICATO, 1982; MAUTNER, 1999). Para Dantas (2018), os migrantes estavam mais sujeitos a isto, pois estavam submetidos a uma espoliação rural em sua terra de origem, decorrente da abolição da escravatura, que deixou grande contingente de negros sem propriedade e trabalho nas áreas rurais.

Abordar a formação da Zona Leste pela ótica da ocupação migrante e imigrante teve como objetivo a tentativa de convergir a questão racial pela releitura de estudos urbanos e históricos sobre a região e sua implicação na expansão das escolas públicas e privadas. Na atualidade, vê-se o reflexo desta divisão racial na população por prefeituras regionais: 
Tabela 2- População por etnia das prefeituras regionais

\begin{tabular}{c|c|c|c|c|cc}
\hline & População (2010) & \% brancos & \% negros* & \% amarelos & \% indígenas \\
\hline Mooca & 343980 & 80.1 & 16.9 & 2.8 & 0.2 \\
\hline Vila Prudente & 246589 & 75.7 & 22.1 & 2.2 & 0.0 \\
\hline Aricanduva & 267702 & 74.3 & 21.8 & 3.8 & 0.1 \\
\hline Penha & 474659 & 66.7 & 31.3 & 2.0 & 0.1 \\
\hline Sapopemba & 284524 & 57.6 & 41.7 & 0.6 & 0.1 \\
\hline Ermelino Matarazzo & 207509 & 58.8 & 39.4 & 1.6 & 0.1 \\
\hline São Mateus & 426794 & 53.9 & 45.0 & 1.0 & 0.1 \\
\hline Itaquera & 523848 & 55.0 & 43.9 & 1.0 & 0.1 \\
\hline São Miguel & 369496 & 49.3 & 49.9 & 0.8 & 0.1 \\
\hline Itaim Paulista & 373127 & 45.9 & 53.4 & 0.7 & 0.1 \\
\hline Guaianases & 268508 & 45.1 & 54.3 & 0.4 & 0.1 \\
\hline Cidade Tiradentes & 211501 & 43.4 & 56.1 & 0.4 & 0.1 \\
\hline
\end{tabular}

Fonte: Dados do IBGE agregados pelo Infocidade (2016). *Pretos e pardos. Elaboração própria.

As prefeituras regionais de ocupação imigrante (Mooca, Vila Prudente, Aricanduva e Penha) têm uma alta porcentagem de habitantes declarados brancos, com destaque para as três primeiras da tabela 2, com mais de 74\%. Nessas três, a porcentagem de negros não chega a $23 \%$.

Por outro lado, com destaque para São Miguel, Itaim Paulista, Guaianases e Cidade Tiradentes, vemos na tabela 2 que a maioria da população negra habita estas quatro prefeituras regionais, com uma média de 53\% contra 23\% das três primeiras prefeituras regionais da ocupação imigrante. Não só estas quatro, mas Ermelino Matarazzo, São Mateus e Itaquera também tiveram uma ocupação majoritariamente de migrantes nacionais. Ressalta-se que há uma dificuldade de cruzar estes dados com as matrículas de estudantes das escolas públicas e privadas, pois os dados de declaração racial não estão vinculados à matrícula por dependência administrativa. Por isso, assume-se que essa análise tem limitações devido a esse revés. A seguir, tratar-se-á da expansão das escolas por mapa.

\section{As escolas da ocupação imigrante (1900-1935)}

No período anterior à República, os ensinos secundário e superior estavam a cargo do Poder Geral e a instrução elementar era responsabilidade das províncias. Essa primeira etapa era exercida, prioritariamente, pela iniciativa privada desde o tempo colonial e mesmo após a Independência, conforme Haidar (2008). Na província de São Paulo, o ensino oficial da instrução elementar era considerado precário: "A profissão de professor primário era pouco valorizada não apenas em termos de salário, mas igualmente em reconhecimento social” (MARCÍLIO, 2005, p. 72).

Por sua vez, os primeiros anos da República não significaram mudanças no que diz respeito à educação elementar, segundo Nagle (1976). Foi a partir da década de 1920 que 
transformações começaram a se modelar no âmbito dos Estados, as antigas províncias, que já eram responsáveis pela instrução pública inicial. "Com efeito, tratou-se, no decênio, de substituir o ideário educacional vigente até então, pelos princípios da nova teoria educacional representada pelo escolanovismo." (NAGLE, 1976, p. 190). ${ }^{10}$

0 ensino confessional havia perdido parte de sua força após a Proclamação da República, como a retirada do ensino religioso na Constituição de 1891. Contudo, a influência da Igreja Católica na área educacional se reestruturou no Governo Vargas, materializada em 1931 na legalização do ensino religioso facultativo nas escolas públicas, consoante Schwartzman, Bomeny, Costa (2000). A forte preocupação com os conteúdos escolares tinha como meta impedir a secularização da educação proposta pelos escolanovistas, vista como uma ameaça social, pois poderia abrir caminho para uma revolução comunista. De forma geral, o Estado, mesmo em um regime autoritário como de Vargas, não conseguiu se separar da dominação religiosa, pois precisou negociar com a instituição para dar cabo aos seus objetivos políticos. Para os autores, a oposição da Igreja Católica ao movimento da Escola Nova permitiu que seus precursores, como Anísio Teixeira, fossem levados ao ostracismo.

Naquela conjuntura, o projeto educativo das Forças Armadas ganhou um novo impulso, pois "o conteúdo dessa pedagogia era a inculcação de princípios de disciplina, obediência, organização, respeito à ordem e às instituições.” (SCHWARTZMAN; BOMENY; COSTA, 2000, p. 84). Os autores completam: "A vinculação da educação às questões de segurança nacional confirma a ideia de que, no Estado Novo, a educação deveria constituir-se em um projeto estratégico de mobilização controlada." (SCHWARTZMAN; BOMENY; COSTA, 2000, p. 86). Isto porque compreendia-se o papel central da escola elementar, à qual não era dada atenção no período anterior, como propagadora da ideologia governamental. Um dos objetivos era a construção de uma identidade nacional como contrapartida da pluralidade cultural decorrente da imigração, por isso a aproximação com a Igreja e os militares.

Neste sentido, a mudança no ensino elementar iniciada na década de 1920 pelos escolanovistas sofre uma guinada ideológica nos anos de 1930. Nas palavras de Schwartzman, Bomeny, Costa (2000, p. 194-195): "Ficava explícita, assim, uma de suas grandes divergências com o movimento da Escola Nova: enquanto esta via na educação um instrumento de neutralização das desigualdades sociais, a Igreja a percebia como tendo por finalidade a adaptação dos desiguais a uma ordem social naturalmente hierárquica”. Mesmo com as reformas, o ensino primário continuou sob a tutela dos Estados e o ensino secundário sob a tutela do governo federal, pelo qual se implantou a formação técnica profissionalizante.

Na transição do século XIX para o XX, a expansão das escolas privadas e das escolas públicas primárias estava a todo vapor em São Paulo. 0 crescimento populacional devido à imigração, à primeira fase da industrialização e ao contexto político compuseram o panorama da ocupação imigrante no lado leste da cidade.

10- Um dos líderes do movimento escolanovista foi Anísio Teixeira, que rompeu com a Igreja Católica, defendendo uma escola pública e laica depois de seus estudos nos Estados Unidos, influenciado pelos ensinamentos de Jonh Dewey (NUNES, 2001). 
Para Perosa (2009, p. 48), havia uma negação da dimensão comercial da oferta privada confessional que se consolidava nas regiões mais elitizadas da cidade. No período de instalação dessas escolas já havia um mercado escolar com estratégias de criação de demandas, concorrência entre as escolas, hierarquias entre os diplomas e diferentes mensalidades segundo a clientela atendida. Uma das estratégias utilizadas para amenizar a dimensão comercial e legitimar o caráter filantrópico do ensino das escolas confessionais era instalar estabelecimentos em regiões mais pobres. À medida que o subúrbio leste se expandia, as escolas públicas e privadas estavam sendo fundadas concomitantemente à formação da ZL desde o começo do século XX, como destacamos na tabela 3:

Tabela 3- Primeiras escolas públicas e privadas da ZL (1900-1935)

\begin{tabular}{|c|c|c|c|}
\hline Ano & Escola & Dep. Adm. & Distrito \\
\hline 1905 & E.E. Orestes Guimarães & Pública & Pari \\
\hline 1909 & E.E. Amadeu Amaral & Pública & Belém \\
\hline 1911 & E.E. Carlos de Campos & Pública & Brás \\
\hline 1913 & E.E. Anchieta Padre & Pública & Brás \\
\hline 1913 & E.E. Santos Dumont & Pública & Penha \\
\hline 1914 & E.E. Oswaldo Cruz & Pública & Mooca \\
\hline 1918 & Colégio Santa Catarina & Privada & Mooca \\
\hline 1925 & E.E. Visconde de Congonhas do Campo & Pública & Tatuapé \\
\hline 1926 & Colégio São Francisco de Assis & Privada & Tatuapé \\
\hline 1926 & Colégio São Vicente de Paulo & Privada & Penha \\
\hline 1928 & E.E. Doutor Antonio de Queiroz Telles & Pública & Mooca \\
\hline 1931 & Colégio Espirito Santo & Privada & Tatuapé \\
\hline 1932 & Escola São José & Privada & Vila Matilde \\
\hline 1932 & E.E. Republica do Paraguay & Pública & Vila Prudente \\
\hline 1932 & E.E. Professora Maria Augusta de Ávila & Pública & Artur Alvim \\
\hline 1933 & E.E. Professor Theodoro de Moraes & Pública & Água Rasa \\
\hline 1933 & E.E. Barão de Ramalho & Pública & Penha \\
\hline 1935 & E.E. Pedro Taques & Pública & Guaianases \\
\hline
\end{tabular}

Fonte: Cadastro de Escolas Secretaria da Educação. "Relação de Escolas Ativas com Data do Ato de Autorização/ Criação". Data base: 02/05/2016. Elaboração própria.

As primeiras escolas públicas da ZL coincidem com a mancha urbana até 1929 (ver mapa 2), correspondente ao aumento populacional dos imigrantes que se instalaram nos distritos do Brás, Belém e Mooca. Todas as escolas privadas estão na ocupação imigrante. Apesar do número inferior de estabelecimentos em relação ao público, presume-se que o número tenha sido maior, pois os dados oficiais da SEE só forneciam as escolas ativas na atualidade. As escolas privadas que foram fechadas ao longo do tempo não puderam ser contabilizadas.

0 primeiro colégio privado data de 1918 e, como todos os outros confessionais, tiveram o caráter missionário de uma "educação cristã", conforme os históricos oficiais dos colégios apresentados na internet. Os colégios católicos participaram da formação da elite paulistana (ALMEIDA, 2009), mas também estiveram presentes nas localidades menos prestigiadas (PEROSA, 2009), pois são a continuidade de um processo histórico no qual 
a Igreja Católica representava parte da educação formal brasileira. A instituição religiosa reestruturou-se na antiga República, conforme Miceli (1985), ampliando seus domínios mesmo depois da separação entre o Estado e a Igreja na Proclamação da República.

As escolas confessionais privadas e públicas demonstram que o processo da expansão da periferia, ou subúrbio, como era conhecido na época, foi mais complexo do que se tem discutido sobre a produção desse espaço urbano, demonstrada no mapa 4, a seguir.

Mapa 4- Escolas Públicas e Privadas da Ocupação Imigrante - Zona Leste

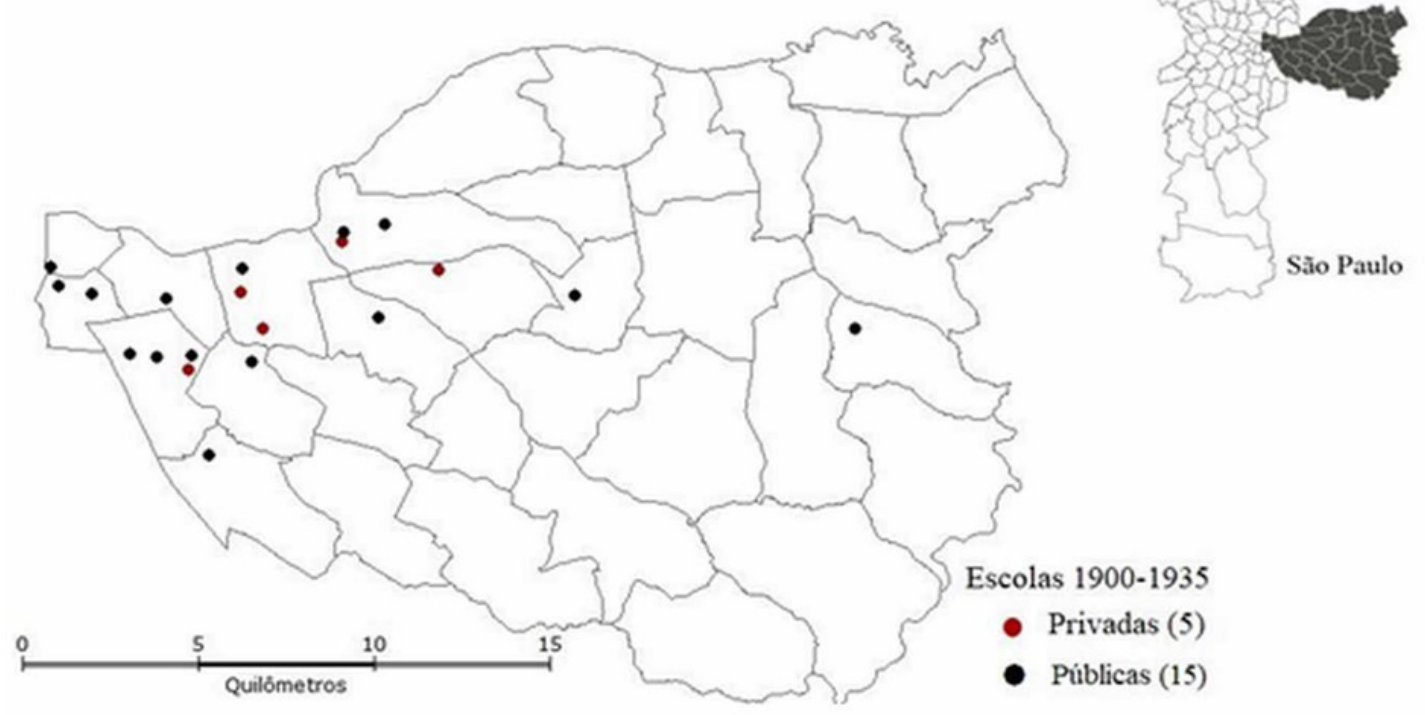

Fonte: CEM, 2012, 2013, 2016 (Censo 2013 INEP/MEC). Cadastro de Escolas da SEE, 2016”. Elaboração própria.

\section{As escolas da ocupação migrante (1935-1964)}

A ocupação migrante coincide com a fase da industrialização pesada no Brasil, liderada pela política desenvolvimentista de Getúlio Vargas, pela qual o Estado brasileiro implantou várias empresas estatais, o que fomentou a migração interna para atender à necessidade de mão-de-obra nacional (CANO, 2015; PAIVA, 2004). As indústrias da ZL foram radicadas ao longo da várzea do rio Tietê, acompanhando a linha férrea, assim como no município de Guarulhos, do outro lado do rio (TOLED0, 2011).

A periferia não foi preparada para receber o novo contingente populacional, que foi submetida à espoliação urbana, como mencionado anteriormente. Nem o Estado, muito menos os industriais, se responsabilizaram pela infraestrutura necessária para recebê-lo, como tinha acontecido com os estrangeiros, reforçando o estigma dos nordestinos como responsáveis pelos problemas urbanos.

Todavia, grande parte da população migrante que chegava à ZL não tinha condições de pagar pelo ensino privado. A espoliação urbana da periferia fomentou os movimentos 
sociais que eclodiram na região reivindicando desde infraestrutura básica até direitos sociais, como educação (ANDRADE, 1989; IFFLY, 2010; SADER, 1988; SPOSITO, 2002). Esses atores dos movimentos sociais vivenciaram a eclosão do populismo ${ }^{11}$, que foi ao encontro dos anseios das classes populares que desejavam educar seus filhos. A organização popular contribuiu para a mudança da paisagem urbana por causa do intenso processo reivindicatório, que levou o poder público a abrir novas escolas públicas, como demonstra o mapa 5, a seguir.

Mapa 5- Escolas Públicas e Privadas da Ocupação Migrante - Zona Leste

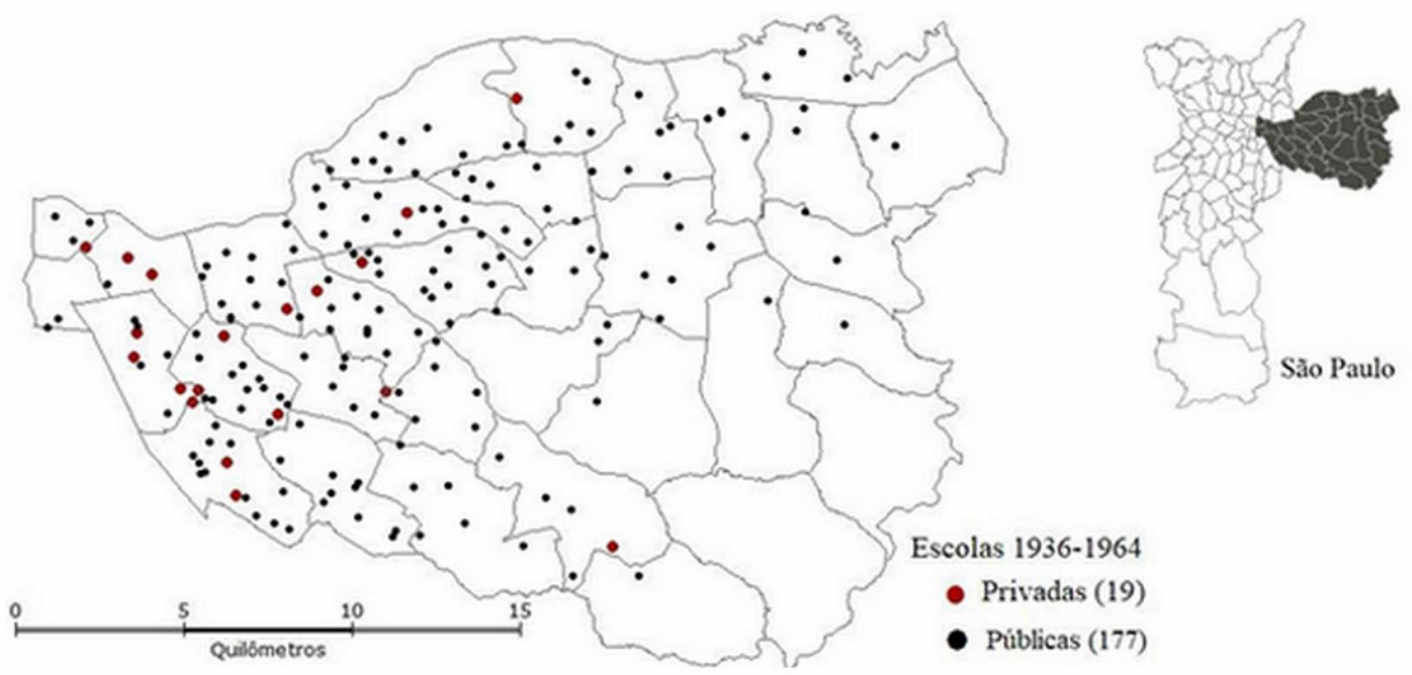

Fonte: CEM, 2012, 2013, 2016 (Censo 2013 INEP/MEC). Cadastro de Escolas da SEE, 2016. Elaboração própria.

A partir da década de 1950, o ritmo da fundação de escolas públicas muda completamente: três escolas entre 1936 a 1940; dezoito entre 1941 e 1950; cento e cinquenta e seis estabelecimentos entre 1951 e 1964, ano do golpe militar de 1964, que se constitui o limite de apresentação desses dados ${ }^{12}$. Os poucos recursos disponíveis para as áreas sociais, como educação, faziam com que esses estabelecimentos fossem instalados de forma improvisada, com a criação de galpões de madeira, por exemplo.

0 trabalho de Sposito (2002) demonstrou que a década de 1950 foi um marco para a escola pública, devido à força popular que negociou com o poder público, que, por sua vez, estava sensibilizado com as reivindicações da periferia. Isto promoveu uma ampliação escolar singular da rede pública na história de São Paulo. Ainda que o aumento tenha ocorrido de forma precária, ultrapassou algumas barreiras, pois, além da ampliação

11- Para Weffort (2003), o populismo foi caracterizado como uma mobilização de raízes urbanas, pois processos como as migrações e a expansão dos meios de comunicação permitiram que a população analfabeta da área rural participasse politicamente.

12- Na tese de Dantas (2018), o processo de expansão da escola privada nos anos seguintes foi feito sem a comparação da escola pública. Pelo limite desse artigo não foi possível trazer essa discussão. 
do ensino elementar, reivindicou a criação de grupos escolares de ensino secundário, nível ainda bastante elitizado naquele período.

Por outro lado, ainda na era getulista, a novidade na rede privada se deu pela preparação da mão de obra desses novos trabalhadores. Isto porque o governo de Vargas delegou às indústrias a qualificação profissional de seus quadros por meio de leis orgânicas (ROMANELLI, 2006, p. 155). Assim, criou-se o "Serviço Nacional Aprendizagem Industrial" (SENAI), em 1942, e o Serviço Social da Indústria (SESI), em 1946. Apesar de ser uma empresa privada, os recursos para financiá-los eram provenientes de encargos da seguridade social (REPAS, 2008), apontando para a tradição do uso de recursos públicos no setor privado na área da educação (OLIVEIRA, 2009). No período da ocupação migrante, apareceram três escolas profissionalizantes desse sistema de ensino, sendo a primeira a Escola SENAI Felício Lanzara, no distrito da Mooca, em 1942, conforme a tabela $4^{13}$ a seguir.

Tabela 4- Escolas privadas da ocupação migrante (1936-1965)

\begin{tabular}{|c|c|c|}
\hline Ano & Escola & Distrito \\
\hline 1939 & Colégio Mary Ward & Carrão \\
\hline 1939 & Colégio Santo Antônio de Lisboa & Tatuapé \\
\hline 1940 & Colégio Joao XXIII & Vila Prudente \\
\hline 1941 & Colégio Nossa Senhora de Lourdes & Água Rasa \\
\hline 1941 & Colégio Franciscano Nossa Senhora do Carmo & Vila Prudente \\
\hline 1942 & Escola Senai Felício Lanzara & Mooca \\
\hline 1943 & Colégio Bom Jesus - Vicente Pallotti & Vila Matilde \\
\hline 1949 & Externato Nossa Senhora Sagrado Coração & Vila Formosa \\
\hline 1953 & Escola Santa Izildinha & São Mateus \\
\hline 1954 & Colégio Olivetano & Penha \\
\hline 1955 & Instituto Nossa Senhora Auxiliadora & Belém \\
\hline 1956 & Educandário Nossa Senhora Aparecida & Vila Prudente \\
\hline 1956 & Colégio São Judas Tadeu & Mooca \\
\hline 1958 & Externato Nossa Senhora Menina & Água Rasa \\
\hline 1958 & Colégio Franciscano São Miguel Arcanjo & Vila Prudente \\
\hline 1958 & Escola Santa Maria & Pari \\
\hline 1962 & Colégio Parque Sevilha & São Lucas \\
\hline 1964 & Centro Educacional Sesi 074 & Ermelino Matarazzo \\
\hline 1964 & Externato São Rafael & Mooca \\
\hline 1964 & Centro Educacional Sesi 032 & Belém \\
\hline
\end{tabular}

Fonte: Cadastro de Escolas Secretaria da Educação. "Relação De Escolas Ativas Com Data Do Ato De Autorização/Criação”. Data base: $02 / 05 / 2016$. Elaboração própria.

13- Não foi possível fazer uma tabela com as escolas públicas devido à quantidade (177 estabelecimentos). 
Dentre as escolas ainda ativas na atualidade, totalizam-se dezenove estabelecimentos privados, sendo a maioria confessional, corroborando que a educação religiosa tinha um forte apelo social. A concentração dessas escolas estava nas prefeituras regionais mais antigas, como Mooca, Penha e Vila Prudente. 0 histórico de criação é semelhante ao do período anterior, que consistia em uma visão missionária para atender os mais pobres. $\mathrm{Na}$ atualidade, são escolas de prestígio que se valem do apelo da educação católica como instrumento de formação humana, apresentando-se como critério para a escolha da instituição por parte dos pais.

A segunda novidade das escolas privadas foi a instalação de instituições abertas por pessoas físicas e não por ordens religiosas. Entretanto, duas delas se utilizaram de nomes religiosos para seu estabelecimento: a Escola Santa Izildinha (1953) e o Colégio São Judas Tadeu (1956) ${ }^{14}$.

A Escola Santa Izildinha foi fundada em 1953, em São Mateus. Apesar do nome de santa, ela foi fundada por uma fiel da Igreja e não por uma ordem católica. Por sua vez, a escola São Judas Tadeu foi criada por um casal de professores, oriundos do interior de São Paulo, que percebeu um déficit educacional na região. De início, era um curso preparatório para o exame de admissão ao antigo ginásio (correspondente ao atual Ensino Fundamental II). Aquela iniciativa teve grande sucesso e outras salas foram ampliadas para atender à demanda.

Os agentes privados não religiosos da área educacional perceberam a carência das escolas e abriram seus próprios estabelecimentos. Como professores, eles possuíam o capital cultural necessário para atentar-se para a lacuna da época a ponto de empreender e viabilizar um negócio. 0 terceiro estabelecimento fundado pela iniciativa de leigos, o Colégio Sevilha, em 1962, tem um nome secular, fugindo à tradição católica.

Essas iniciativas demonstram que, durante o processo de expansão da periferia, agentes privados viram no setor educacional uma oportunidade de oferecimento de serviço à população. Elas sugerem que a escola privada era a dependência administrativa que proporcionaria a educação condizente com uma fração de classe que se estabelecia nesses novos espaços urbanos. Ainda são necessárias pesquisas qualitativas para verificação dessas hipóteses. Entretanto, é fato que havia demanda para a oferta apresentada, pois esses colégios se consagraram ao longo do tempo como referências na região.

Assim, apesar do Estado ser o provedor e regulador da educação, o princípio da pluralidade e liberdade de escolha das famílias tem possibilitado historicamente a oferta privada educacional. É importante salientar que as matrículas na dependência privada sempre foram menores do que na pública. Seu acesso por meio de mensalidades separa seus alunos pela via financeira, não se constituindo, assim, uma escolha (CURY, 2008).

\section{Considerações finais}

Este artigo veio demonstrar que a presença da escola privada na periferia leste de São Paulo data do início do século XX. Portanto, não se trata de um fenômeno novo, mas

14- As informações foram retiradas dos sites oficiais dos colégios. Santa Izildinha, disponível em: http://staizildinha.com.br/iesi/historicomenina-izildinha-iesi/. Acesso em: 27 set. 2016. São Judas Tadeu, disponível em: https://www.usjt.br/a-sao-judas/. Acesso em: 29 set. 2018. 
que esteve presente concomitantemente à formação da periferia. É importante salientar que a experiência da expansão das escolas da ZL é bem específica de São Paulo, portanto não se trata de pensar em generalizações. Contudo, sua configuração no contexto social e histórico pode contribuir para se pensar sobre alguns sentidos da educação brasileira.

A tese de que a presença da escola privada na periferia não é recente aponta para a força política e social, especialmente da educação confessional, no sistema educacional ao longo do tempo. Há uma naturalização da coexistência das escolas privadas sem o questionamento do que isto representa na totalidade do sistema de ensino, para além da mercantilização, tão bem discutida por diversos autores (FONSECA, 1992; GENTILI, 1995; OLIVEIRA, 2009) que denunciam as políticas neoliberais aprofundadas a partir das décadas de 1990. 0 ensino elementar oferecido pela escola privada teve sua primazia antes mesmo da escola elementar pública republicana (DANTAS, 2018). Sua força política foi demonstrada contra o projeto escolanovista e na sua participação na regulamentação educacional, concedendo ao ensino privado pouca ingerência estatal na sua atuação. Ao longo do tempo, conforme Cury (2008), a influência dos setores privados na educação teve sua presença assegurada nas Leis de Diretrizes e Bases, inclusive na atual (de 1996), que permitiam repasses de recursos públicos para escolas confessionais e filantrópicas.

Desde os tempos coloniais, havia uma lacuna sobre um projeto de escola elementar pública e gratuita, que os percussores da Escola Nova lutaram nos anos de 1920-1930, tendo como opositores a tradição escolar privada e confessional principalmente. A expansão da escola pública elementar esteve atrelada a se contrapor a uma educação proposta pelos imigrantes, que, no período de Vargas, era vista como uma ameaça. Essa mão-de-obra, que outrora fora incentivada com o intuito do branqueamento da nação, estava sendo substituída, naquele momento, por migrantes nacionais, oriundos principalmente da Região Nordeste, recompondo racialmente a cidade de São Paulo, sobretudo a periferia leste.

Ao trazer a proposta da ocupação imigrante e migrante para a análise das escolas, demonstra-se que a ZL passou por processos próprios nos quais a questão racial estava presente. Defendeu-se a análise, considerando o fator racial, a partir da releitura de estudos sobre a periferia. Isto porque textos clássicos, alguns apresentados ao longo deste texto, tangenciam o fato, indicando que a maioria de migrantes internos eram estigmatizados por serem nordestinos e negros, sem eleger tal critério como estruturante das relações.

Ao se associar a expansão das escolas à formação da periferia é possível trazer à baila a crítica de Oliveira (2013), que consiste na ausência do fator racial nas análises da segregação urbana, elegendo o fator socioeconômico como a principal questão de análise. Crítica esta que deve ser estendida às análises das desigualdades educacionais.

Durante o crescimento da periferia, diversos atores assimilaram aquela conjuntura como a oportunidade de empreender no mercado educacional, abrindo novas escolas devido ao déficit educacional. Não apenas a Igreja Católica, mas outros agentes, como, por exemplo, professores, vislumbraram a oportunidade de oferecer seus serviços a frações de classes com mais recursos financeiros na ZL, que tinham capital para investir em educação paga. Tais agentes de assimilação contribuíram para a transformação do território, e seus empreendimentos se consagraram ao longo do tempo. 
Por sua vez, os migrantes que vieram para São Paulo tinham pouca ou nenhuma educação formal e na cidade lutaram para que seus filhos pudessem frequentar a escola pública. Isto remete a outro sentido, que consiste na força da participação política que contribuiu para o fortalecimento da expansão da educação pública. Tal contexto abriu espaços para políticos que fugiam da tradição elitista, mas que identificaram na demanda popular uma oportunidade no jogo político. 0 populismo foi a inflexão que permitiu a experiência de participação popular, que redundou em mudanças no cenário da escola pública na ZL. Estes foram agentes de resistência que se organizaram em movimentos sociais para reivindicar melhorias, não só na infraestrutura, como no campo educacional.

Por outro lado, a participação popular dos migrantes internos é pouco associada a uma reivindicação da escola pública na periferia por parte dos negros. Esta provocação precisa ser mais elaborada e discutida, mas os dados podem sugeri-las, o que poderia ser realizado em pesquisas futuras. Evidentemente, mesmo com toda essa mobilização que resultou no aumento da escola pública na região, ao se tratar do conflito social, pode se perceber que ela não se deu como um projeto que viesse competir em qualidade com a escola privada que servia à população mais escolarizada historicamente.

\section{Referências}

ALBUQUERQUE JR, Durval. A invenção do nordeste e outras artes. 4. ed. São Paulo: Cortez, 2009.

ALMEIDA, Ana Maria. As escolas dos dirigentes paulistas: ensino médio, vestibular, desigualdade social. Belo Horizonte: Argvmentvm, 2009.

ALMEIDA, Ana Maria; NOGUEIRA, Maria Alice (org.). A escolarização das elites: um panorama internacional da pesquisa. 2. ed. Petrópolis: Vozes, 2003.

ALMEIDA, Silvio. 0 que é racismo estrutural? Belo Horizonte: Letramento, 2018. (Feminismos plurais).

ANDRADE, Cleide. As lutas sociais por moradia de São Paulo: a experiência de São Miguel Paulista e Ermelino Matarazzo. 1989. Dissertação (Mestrado em Ciências Sociais) - Pontifícia Universidade Católica de São Paulo, São Paulo, 1989.

ANDRADE, Margarida. Brás, Mooca e Belenzinho - "bairros italianos" na São Paulo Além-Tamanduateí. Revista do Departamento de Geografia, São Paulo, n. 8, p. 97-102, 1994.

BRASIL. Lei de Diretrizes e Bases da Educação Nacional. Lei n 9.394, de 20 de dezembro de 1996. Brasília, DF: [s. n.], 1996.

CAMARG0, Candido et al. São Paulo 1975: crescimento e pobreza. 5. ed. São Paulo: Loyola, 1976.

CAMELO, Rafael. A educação privada em São Paulo: expansão e perspectivas. São Paulo: Fundação Seade. (1ª análise Seade; n. 19.out. 2014). 
CANO, Wilson. Crise e industrialização no Brasil entre 1929 e 1954: a reconstrução do Estado Nacional e a política nacional de desenvolvimento. Revista de Economia Política, São Paulo, v. 35, n. 3, p. 444-460, set. 2015.

CARONE, Edgar. A evolução industrial de São Paulo (1889-1930). São Paulo: Senac, 2001.

CEM. Centro de Estudos da Metrópole. Base cartográfica digital georreferenciada das escolas da região metropolitana de São Paulo. São Paulo: CEM, 2013.

CEM. Centro de Estudos da Metrópole. Base de divisão territorial da Região Metropolitana de São Paulo (2010). São Paulo: CEM, 2012.

CEM. Centro de Estudos da Metrópole. Base de escolas georreferencidas na região metropolitana de São Paulo (2013). São Paulo: CEM, 2016.

COLLINS, Randall. Quatro tradições sociológicas. Petrópolis: Vozes, 2009.

CURY, Carlos Jamil. Um novo movimento da educação privada. In: ADRIÃO, Theresa; PERONI, Vera (org.). Público e privado na educação: novos elementos para o debate. São Paulo: Xamã, 2008. p. 17-26.

DANTAS, Adriana Santiago Rosa. As escolas privadas da periferia de São Paulo: uma análise desde a colonialidade do poder à brasileira. 2018. Tese (Doutorado em Educação) - Faculdade de Educação, Universidade de São Paulo, São Paulo, 2018.

DANTAS, Adriana Santiago Rosa. Por dentro da quebrada: a heterogeneidade social de Ermelino Matarazzo e da periferia. 2013. Dissertação (Mestrado em Estudos Culturais) - Escola de Artes, Ciências e Humanidades, Universidade de São Paulo, São Paulo, 2013.

DEAN, Warren. A industrialização de São Paulo (1880-1945). 4. ed. Rio de Janeiro: Bertrand Brasil, 1991.

DOMINGUES, Petrônio. Uma história não contada: negro, racismo e branqueamento em São Paulo no pós-abolição. São Paulo: Senac, 2004.

ELIAS, Norbert; SCOTSON, John. Os estabelecidos e os Outsiders: sociologia das relações de poder a partir de uma pequena comunidade. Rio de Janeiro: Jorge Zahar, 2000.

FONSECA, Dirce. 0 pensamento privatista em educação. Campinas: Papirus, 1992. (Magistério: formação e trabalho pedagógico).

FONTES, Paulo. Trabalhadores e cidadãos: Nitro Química: a fábrica e as lutas operárias nos anos 50. São Paulo: Annablume, 1997.

FONTES, Paulo. Um nordeste em São Paulo: trabalhadores migrantes em São Miguel Paulista (1945-66). Rio de Janeiro: FGV, 2008.

GENTILI, Pablo (org). Pedagogia da exclusão: o neoliberalismo e a crise da escola pública. Petrópolis: Vozes, 1995 
GÓES, Weber. Racismo, eugenia no pensamento conservador brasileiro: a proposta de povo em Renato Kehl. 2015. Dissertação (Mestrado em Ciências Sociais) - Faculdade de Filosofia e Ciências, Universidade Estadual Paulista "Júlio de Mesquita Filho", Marília, 2015.

GOMES, Lisandra Ogg; NOGUEIRA, Maria Alice. A excelência escolar em uma escola pública de ensino médio. Educação em Foco, Belo Horizonte, v. 20, n. 30, p. 189-208, Jan./abr. 2017.

HAIDAR, Maria de Lourdes Mariotto. 0 ensino secundário no Brasil Império. 2. ed. São Paulo: Edusp, 2008.

HASENBALG, Carlos; SILVA, Nelson do Valle. Educação e diferenças raciais na mobilidade ocupacional do Brasil. In: HASENBALG, Carlos; SILVA, Nelson do Valle; LIMA, Márcia. Cor e estratificação social. Rio de Janeiro: Contra Capa, 1999, p. 218-231.

IFFLY, Catherine. Transformar a metrópole: Igreja Católica, territórios e mobilizações sociais em São Paulo 1970-2000. São Paulo: Edunesp, 2010.

KOWARICK, Lúcio. A espoliação urbana. 2. ed. Rio de Janeiro: Paz e Terra, 1993.

LARA, Silvia. Escravidão, cidadania e história do trabalho no Brasil. Projeto História, São Paulo, v. 16, p. 25-38, fev. 1988.

LIMA, Márcia. 0 quadro das desigualdades. In: HASENBALG, Carlos; SILVA, Nelson do Valle; LIMA, Márcia. Cor e estratificação social. Rio de Janeiro: Contra Capa, 1999. p. 232-240.

LIMA, Márcia; PRATES, lan. Desigualdades raciais no Brasil: um desafio persistente. In: ARRETCHE, Marta (org.). Trajetórias das desigualdades: como o Brasil mudou nos últimos cinquenta anos. São Paulo: Edunesp: CEM, 2015. p. 163-192.

MACHADO, Carlos Eduardo. População negra e escolarização na cidade de São Paulo nas décadas de 1920 e 1930. 2009. Dissertação (Mestrado em História Social) - Faculdade de Filosofia, Letras e Ciências Humanas, Universidade de São Paulo, São Paulo, 2009.

MAGALHÃES, Valéria. Memória e história da Zona Leste de São Paulo: nota de pesquisa. In: SANTHIAGO, Ricardo; MAGALHÃES, Valéria Barbosa de (org.). Memória e diálogo: escutas da Zona Leste, visões sobre a história oral. São Paulo: Letra e Voz: Fapesp, 2011. p. 41-60.

MARCÍLO, Maria Luiza. História da escola em São Paulo e no Brasil. São Paulo: Imprensa Oficial do Estado de São Paulo; Instituto Fernand Braudel, 2005.

MARICATO, Ermínia (org.). A produção capitalista da casa e (da cidade) no Brasil industrial. 2. ed. São Paulo: Alfa-Omega, 1982.

MARTINS, José de Souza. Conde Matarazzo, o empresário e a empresa: estudo da sociologia do desenvolvimento. 2. ed. São Paulo: Hucitec, 1974.

MAUTNER, Yvonne. A periferia como fronteira de expansão do capital. In: DEÁK, Csaba; SCHIFFER, Sueli Ramos (org.). 0 processo de urbanização no Brasil. São Paulo: Edusp, 1999. p. 245-259. 
MEDEIROS, Jonas; JANUÁRIO, Adriano. A nova classe trabalhadora e a expansão da escola privada nas periferias da cidade de São Paulo. In: REUNIÃO NACIONAL DA ANPOCS, 38., 2014, Caxambu. Anais... Caxambu: Anpocs, 2014. p. 1-30.

MENEZES FILHO, Naercio; KIRSCHBAUM, Charles. Educação e desigualdades no Brasil. In: ARRETCHE, Marta (org.). Trajetórias das desigualdades: como o Brasil mudou nos últimos cinquenta anos. São Paulo: Edunesp: CEM, 2015. p. 109-132.

MICELI, Sérgio. A elite eclesiástica brasileira (1890-1930). 1985. Tese (Livre Docência em Sociologia) Instituto de Filosofia e Ciências Humanas, Universidade Estadual de Campinas, Campinas, 1985.

MORSE, Richard. Formação histórica de São Paulo (de comunidade a metrópole). São Paulo: Difel, 1970.

NAGLE, Jorge. Educação e sociedade na Primeira República. São Paulo: EPU; Rio de Janeiro: Fundação Nacional de Material Escolar, 1976.

NOGUEIRA, Maria Alice. No fio da navalha - A (nova) classe média brasileira e sua opção pela escola particular. In: ROMANELLI, Geraldo; NOGUEIRA, Maria Alice; ZAGO, Nadir (org.). Família \& escola: novas perspectivas de análise. Petrópolis: Vozes, 2013. p. 109-130.

NUNES, Clarice. Anísio Teixeira: a poesia da ação. Revista Brasileira de Educação, Rio de Janeiro, n. 16, p.5-18, 2001.

OLIVEIRA, Reinaldo. Interfaces entre as desigualdades urbanas e as desigualdades raciais no Brasil: observações sobre o Rio de Janeiro e São Paulo. In: OLIVEIRA, Reinaldo (org.). A cidade e o negro no Brasil: cidadania e território. 2. ed. São Paulo: Alameda, 2013. p. 43-94.

OLIVEIRA, Romualdo. A transformação da educação em mercadoria no Brasil. Educação \& Sociedade, Campinas, v. 30, n. 108, p. 739-760, out. 2009.

PAIVA, Odair da Cruz. Caminhos cruzados: migração e construção do Brasil moderno (1930-1950). Bauru: Edusc, 2004.

PEROSA, Graziela Serroni. Escola e destinos femininos: São Paulo (1950/1960). Belo Horizonte: Argvmentvm, 2009.

PEROSA, Graziela Serroni; DANTAS, Adriana Santiago Rosa. A escolha da escola privada em famílias dos grupos popularesl. Educação e Pesquisa, São Paulo, v. 43, n. 4, p. 987-1004, dez. 2017.

PEROSA, Graziela Serroni, LEBARON, Frédéric, LEITE, Cristiane. 0 espaço das desigualdades educativas no município de São Paulo. Pro-Posições. Campinas, v. 26, n. 2 (77), p. 99-118, maio/ago. 2015.

PREFEITURA DE SÃO PAULO. Infocidade. São Paulo: Prefeitura, 2015. Disponível em http://infocidade. prefeitura.sp.gov.br/. Acesso em: 22 out. 2018. 
REPAS, Marcos. Escola e mobilidade social: um estudo sobre os egressos do Sesi Vila Cisper. 2008. Dissertação (Mestrado em Educação: História, Política, Sociedade) - Pontifícia Universidade Católica de São Paulo, São Paulo, 2008.

RIBEIR0, Darcy. Sobre o óbvio. Marília: Lutas Anticapital, 2019.

RIBEIRO, Luiz. Transformação geofísica e explosão urbana. In: SACHS, Ignacy; WILHEIM, Jorge; PINHEIR0, Paulo Sérgio (org.). Brasil: um século de transformações. São Paulo: Companhia das Letras, 2001. p. 132-161.

ROLNIK, Raquel. A cidade e a lei: legislação, política urbana e territórios na cidade de São Paulo. 3. ed. São Paulo: Studio Nobel: Fapesp, 2003.

ROLNIK, Raquel. Territórios negros nas cidades brasileiras (etnicidade e cidade em São Paulo e Rio de Janeiro). Revista de Estudos Afro-Asiáticos, Universidade Cândido Mendes, Rio de Janeiro, n. 17. p. 29-41, set. 1989.

ROMANELLI, Otaíza. História da educação no Brasil (1930/1973). 30. ed. Petrópolis: Vozes, 2006.

SADER, Eder. Quando novos personagens entraram em cena: experiências, falas e lutas dos trabalhadores da Grande São Paulo, 1970-80. Rio de Janeiro: Paz e Terra, 1988.

SANTOS, Carlos José. Nem tudo era italiano: São Paulo e pobreza: 1890-1915 3. ed. São Paulo: Annablume: Fapesp, 2008.

SCHWARTZMAN, Simon; BOMENY, Helena Maria Bousquet; COSTA, Vanda Maria Ribeiro. Tempos de Capanema. 2. ed. São Paulo: Paz e Terra: Fundação Getúlio Vargas, 2000.

SETTON, Maria da Graça; MARTUCCELLI, Danilo. Apresentação: a escola entre o reconhecimento, o mérito e a excelência. Educação e Pesquisa. São Paulo, v. 41, n.esp., p.1385-1391, 2015.

SIQUEIRA, Ana Rita; NOGUEIRA, Maria Alice. Focalizando um segmento específico da rede privada de ensino: escolas particulares de baixo custo. Educação e Pesquisa, São Paulo, v. 43, n. 4, p. 1005-1022, 2017.

SPOSITO, Marília. 0 povo vai à escola: a luta popular pela expansão do ensino público em São Paulo. 4. ed. São Paulo: Loyola, 2002.

TOLEDO, Edilene. Guarulhos, cidade industrial: aspectos da história e do patrimônio da industrialização num município da Grande São Paulo. Revista Mundos do Trabalho, Florianópolis, v. 3, n. 5, p. 166-185, 2011.

WEFFORT, Francisco. 0 populismo na política brasileira. 5. ed. Rio de Janeiro: Paz e Terra, 2003.

Recebido em: 22.08.2019

Revisado em: 28.04.2020

Aprovado em: 14.09.2020 
Adriana Santiago Rosa Dantas é pós-doutoranda em educação pela Universidade Estadual de Campinas (Unicamp), mestra em Estudos Culturais e doutora em Educação pela Universidade de São Paulo (USP). Bolsista Fapesp (Processo 2019/09919-3). 